\title{
Adjuvant chemotherapy improves survival in patients with completely resected T3NO non-small cell lung cancer invading the chest wall
}

\author{
Justin A. Drake, MD, Jennifer L. Sullivan, MD, and Benny Weksler, MD, MBA
}

\section{ABSTRACT}

Objective: Adjuvant chemotherapy prolongs survival in patients with non-small cell lung cancer with N1 disease or tumors larger than $4 \mathrm{~cm}$. Patients with T3N0 disease due to chest wall invasion often receive adjuvant chemotherapy because their disease is classified as stage II non-small cell lung cancer. This study evaluated whether chemotherapy improves survival after complete resection of T3N0 non-small cell lung cancer with invasion of the chest wall.

Methods: Patients who underwent complete resection of N0 non-small cell lung cancer with invasion of the chest wall were identified in the National Cancer Database. We performed propensity matching of patients who received adjuvant chemotherapy and patients who did not and examined survival.

Results: We identified 2326 eligible patients; 1050 patients (45\%) received adjuvant chemotherapy, and 1276 patients $(55 \%)$ did not. Patients who received chemotherapy after surgery had significantly better median survival than patients who did not (71 vs 39 months, $P<.001$ ). We identified 772 matched pairs. In the matched cohort, patients who received chemotherapy after surgery also had significantly better median survival (68 vs 39 months without chemotherapy, $P<.001)$.

Conclusions: In this large database study, adjuvant chemotherapy significantly improved survival in patients with T3 (chest wall) N0 non-small cell lung cancer after complete resection. Further studies are required to confirm our findings. (J Thorac Cardiovasc Surg 2018;155:1794-802)

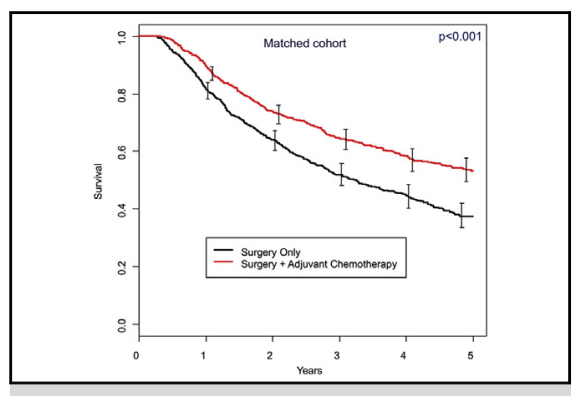

Survival curves of patients undergoing surgery alone versus surgery followed by chemotherapy. Overall survival in the matched cohort.

\section{Central Message}

In a large database study, AC significantly improved survival in patients with $\mathrm{T} 3 \mathrm{~N} 0$ NSCLC with chest wall invasion after complete resection.

\section{Perspective}

Patients with T3N0 NSCLC with chest wall invasion often receive $\mathrm{AC}$ because their disease is classified as stage II. There are no studies specifically examining AC in T3NO NSCLC with chest wall invasion. We found that chemotherapy after resection significantly improves survival. Our findings support AC for T3N0 tumors that invade the chest wall.

See Editorial Commentary page 1803.
Lung cancer remains the number one cause of cancer death in the United States despite an approximately 3\% decrease in incidence per year since 2008. ${ }^{1}$ Stage IIB non-small cell lung cancer (NSCLC), particularly T3 node-negative (N0)

From the Division of Thoracic Surgery, Department of Surgery, University of Tennessee Health Science Center, and West Cancer Center, Memphis, Tenn.

Read at the 97th Annual Meeting of The American Association for Thoracic Surgery, Boston, Massachusetts, April 29-May 3, 2017.

Received for publication April 30, 2017; revisions received Oct 21, 2017; accepted for publication Nov 12, 2017; available ahead of print Jan 17, 2018.

Address for reprints: Benny Weksler, MD, MBA, Division of Thoracic Surgery, University of Tennessee Health Science Center, 1325 Eastmoreland Ave, Suite 460, Memphis, TN 38104 (E-mail: bweksler@uthsc.edu).

$0022-5223 / \$ 36.00$

Copyright (c) 2017 by The American Association for Thoracic Surgery

https://doi.org/10.1016/j.jtcvs.2017.11.091 tumors with chest wall invasion, is best treated with surgical resection. Completeness of resection and nodal status are the most important factors influencing local recurrence and overall survival. ${ }^{2-4}$

Multiple randomized controlled trials have suggested that the administration of adjuvant cisplatin-based chemotherapy may prolong survival in selected patients with N1

Scanning this QR code will take you to a supplemental video. To view the AATS Annual Meeting Webcast, see the URL next to the webcast thumbnail. 


\section{Abbreviations and Acronyms \\ $\mathrm{AC}=$ adjuvant chemotherapy \\ CDS = Charleston-Deyo Score \\ $\mathrm{CI}=$ confidence interval \\ $\mathrm{NCDB}=$ National Cancer Database \\ NSCLC $=$ non-small cell lung cancer}

disease and tumors larger than $4 \mathrm{~cm}$, whereas other studies showed survival benefit for patients with stage IB to stage IIIA NSCLC. ${ }^{5-8}$ These studies confirmed previous large meta-analyses. One showed a $5.4 \%$ survival benefit of adjuvant cisplatin-based chemotherapy 5 years after resection, ${ }^{9}$ and a another demonstrated a modest $4 \%$ survival benefit for patients with completely resected NSCLC who received chemotherapy. ${ }^{10}$ The benefit of chemotherapy was noted in patients with stage IB NSCLC and above.

The current treatment recommendation for T3NOM0 (stage IIB) NSCLC that invades the chest wall is complete resection and administration of adjuvant chemotherapy (AC). ${ }^{11}$ This is largely based on the randomized trials mentioned and is an inference from the benefit of adjuvant therapy in stage IIB (positive N1 nodes)..$^{5-8,12-15}$ There have been no studies directly evaluating the value of $\mathrm{AC}$ in patients with T3N0 tumors that invade the chest wall, and previous randomized trials did not specifically address this question. The purpose of this study was to investigate the role of AC after complete resection (R0) in patients with NSCLC with chest wall invasion.

\section{MATERIALS AND METHODS}

We extracted lung cancer data from the National Cancer Database (NCDB) using 2013 participant use forms. The NCDB is co-sponsored by the American College of Surgeons and the American Cancer Society, and serves as a repository for clinical oncology data from the Commission-on-Cancer-accredited facilities across the United States. Each year, data from more than 1500 facilities, totaling approximately $70 \%$ of all new cancer diagnoses in the United States, are collected. ${ }^{16}$ The NCDB data are completely de-identified; therefore, this study was deemed exempt from the requirement for informed consent by the Institutional Review Board of the University of Tennessee Health Science Center.

The NCDB was queried for all patients with NSCLC invading the chest wall who underwent complete surgical resection. Specific codes describing chest wall involvement in the form of parietal pleura and rib invasion were used to select patients for the study. We excluded patients who died within 90 days, who had incomplete resection, who had positive nodal disease, who had distant metastases, who had final pathologic other than IIB, and who had received preoperative chemotherapy or radiotherapy. We also excluded patients with no information on tumor size and those with incomplete or miscoded information on vital status.

\section{Statistical Analysis}

Patient characteristics are reported using mean \pm standard deviation or median and interquartile range for continuous variables and frequencies and percentages for categoric variables. Pearson's chi-square test was used to compare categoric variables, and Student $t$ test was used to compare continuous variable.
Propensity matching was performed, creating balanced cohorts of patients with tumors invading the chest wall who received or did not receive AC. Propensity matching was performed using a logistic regression model that generated scores on the basis of the following variables: age, sex, race, year of diagnosis, insurance status, type of institution where the patient received treatment, Charlson-Deyo Score (CDS), tumor grade, tumor histology, sequence number (number of cancers other than lung cancer each patient had), extent of resection (wedge resection, segmentectomy/lobectomy, pneumonectomy), and adjuvant radiotherapy. We used the recommended caliper width of 0.2 times the standard deviation of the logit of the propensity score. ${ }^{17}$ Further, we used standardized differences to compare characteristics before and after the match using values less than 10 to indicate acceptable balance. ${ }^{18}$ Survival was analyzed by the Kaplan-Meier method with log-rank analysis. Survival analysis was performed using overall survival, defined as the time from diagnosis to death or censoring. In the matched cohort, we used the stratified log-rank test to account for the matched pairs. SAS statistical software package version 9.4 (SAS Institute, Inc, Cary, NC) was used for the analysis.

\section{RESULTS}

A total of 2326 patients underwent complete resection of T3NOM0 NSCLC with chest wall involvement from 2006 to 2012 (Figure 1). The majority were male $(1363,58.6 \%)$, the mean age was $66.9 \pm 10.0$ years, and most of the patients were white $(89.1 \%)$. A total of 1050 patients $(45.1 \%)$ received $\mathrm{AC}$, and 1276 patients $(54.9 \%)$ did not.

Clinical and pathologic data for this cohort are presented in Table 1. Patients who received AC were younger, were

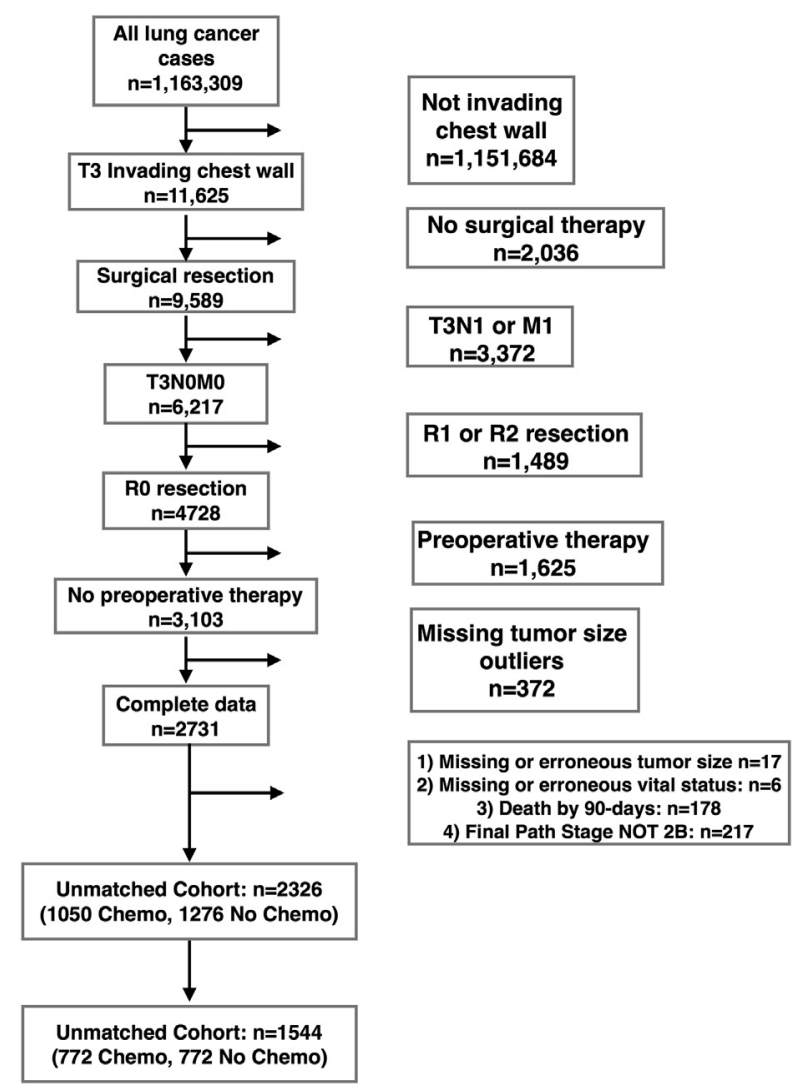

FIGURE 1. Patient selection and cohort creation. 
TABLE 1. Unmatched and matched cohort characteristics for patients with T3NO chest wall after complete resection

\begin{tabular}{|c|c|c|c|c|c|c|}
\hline \multirow[b]{2}{*}{ Characteristic } & \multicolumn{3}{|c|}{ Unmatched cohort } & \multicolumn{3}{|c|}{ Propensity-matched cohort } \\
\hline & $\begin{array}{c}\text { Surgery }+ \text { AC } \\
\quad(n=1050)\end{array}$ & $\begin{array}{c}\text { Surgery } \\
(n=1276)\end{array}$ & $\begin{array}{c}\text { Standardized } \\
\text { difference }(\%)\end{array}$ & $\begin{array}{c}\text { Surgery + AC } \\
(\mathrm{n}=\mathbf{7 7 2})\end{array}$ & $\begin{array}{l}\text { Surgery } \\
(n=772)\end{array}$ & $\begin{array}{r}\text { Standardized } \\
\text { difference }(\%)\end{array}$ \\
\hline Age at diagnosis, $\mathrm{y} \pm \mathrm{SD}$ & $63.0 \pm 9.8$ & $69.5 \pm 9.5$ & 67.0 & $65.5 \pm 8.9$ & $65.5 \pm 9.3$ & 0.5 \\
\hline Sex, n $(\%)$ & & & 1.2 & & & 0.5 \\
\hline Male & $612(58.3)$ & $751(58.9)$ & & $462(59.8)$ & $460(59.6)$ & \\
\hline Female & $438(41.7)$ & $525(41.1)$ & & $310(40.2)$ & $312(40.4)$ & \\
\hline Race, n (\%) & & & 5.0 & & & 5.2 \\
\hline White & $929(88.5)$ & $1144(89.7)$ & & $689(89.2)$ & $677(87.7)$ & \\
\hline Black & $100(9.5)$ & $104(8.2)$ & & $69(8.9)$ & $77(10.0)$ & \\
\hline Other & $21(2.0)$ & $28(2.2)$ & & $14(1.8)$ & $18(2.3)$ & \\
\hline Ethnicity, n (\%) & & & 0.4 & & & 0.8 \\
\hline Hispanic & $27(2.6)$ & $32(2.5)$ & & $21(2.7)$ & $20(2.6)$ & \\
\hline Non-Hispanic & $1023(97.4)$ & $1244(97.5)$ & & $751(97.3)$ & $752(97.4)$ & \\
\hline Year of diagnosis, $\mathrm{n}(\%)$ & & & 9.8 & & & 5.6 \\
\hline 2006 & $139(13.2)$ & $189(14.8)$ & & $98(12.7)$ & $104(13.5)$ & \\
\hline 2007 & $157(15.0)$ & $178(13.9)$ & & $118(15.3)$ & $108(14.0)$ & \\
\hline 2008 & $149(14.2)$ & $197(15.4)$ & & $114(14.8)$ & 107 (13.9) & \\
\hline 2009 & $159(15.1)$ & $169(13.2)$ & & $106(13.7)$ & $114(14.8)$ & \\
\hline 2010 & $137(13.0)$ & $186(14.6)$ & & 107 (13.9) & $109(14.1)$ & \\
\hline 2011 & $146(13.9)$ & $180(14.1)$ & & 107 (13.9) & $110(14.2)$ & \\
\hline 2012 & $163(15.5)$ & 177 (13.9) & & $122(15.8)$ & $120(15.5)$ & \\
\hline Primary payer, $\mathrm{n}(\%)$ & & & 44.9 & & & 5.2 \\
\hline Not insured & $31(3.0)$ & $33(2.6)$ & & $22(2.8)$ & $24(3.1)$ & \\
\hline Private insurance & $434(41.3)$ & $320(25.1)$ & & $278(36.0)$ & $269(34.8)$ & \\
\hline Medicaid & $88(8.4)$ & $52(4.1)$ & & $43(5.6)$ & $47(6.1)$ & \\
\hline Medicare & $471(44.9)$ & $844(66.1)$ & & $411(53.2)$ & $409(53.0)$ & \\
\hline Other/unknown, n (\%) & $26(2.5)$ & $27(2.1)$ & & $18(2.3)$ & $23(3.0)$ & \\
\hline Institution, n (\%) & & & 5.5 & & & 2.4 \\
\hline Academic & $356(33.9)$ & $466(36.5)$ & & $275(35.6)$ & $266(34.5)$ & \\
\hline Other & $694(66.1)$ & $810(63.5)$ & & $497(64.4)$ & $506(65.5)$ & \\
\hline Charlson-Deyo Comorbidity Score, n ( $\%)$ & & & 20.4 & & & 2.9 \\
\hline Score 0 & $538(51.2)$ & $589(46.2)$ & & $384(49.7)$ & $378(49.0)$ & \\
\hline Score 1 & $409(39.0)$ & $475(37.2)$ & & $302(39.1)$ & $301(39.0)$ & \\
\hline Score $>1$ & $103(9.8)$ & $212(16.6)$ & & $86(11.1)$ & $93(12.0)$ & \\
\hline Lung cancer was only malignancy (sequence number) & & & 20.6 & & & 4.7 \\
\hline Yes & $772(73.5)$ & $903(70.8)$ & & 555 (71.9) & $560(72.5)$ & \\
\hline No & $278(26.5)$ & $373(30.2)$ & & $217(28.1)$ & $212(27.5)$ & \\
\hline Primary site, $\mathrm{n}(\%)$ & & & 9.9 & & & 0.3 \\
\hline Upper lobe & $831(79.1)$ & $967(75.8)$ & & $598(77.5)$ & $599(77.6)$ & \\
\hline Middle lobe & $14(1.3)$ & $30(2.4)$ & & $11(1.4)$ & $11(1.4)$ & \\
\hline Lower lobe & $205(19.5)$ & 279 (21.9) & & $163(21.1)$ & $162(21.0)$ & \\
\hline Laterality, n (\%) & & & 3.0 & & & 1.1 \\
\hline Right & $626(59.8)$ & $743(58.4)$ & & $454(58.8)$ & $450(58.3)$ & \\
\hline Left & $420(40.2)$ & $530(41.6)$ & & $318(41.2)$ & $322(41.7)$ & \\
\hline Adenocarcinoma, n (\%) & $474(45.1)$ & $525(41.1)$ & 8.1 & $346(44.8)$ & $346(44.8)$ & 0.0 \\
\hline Grade, n (\%) & & & 11.7 & & & 2.5 \\
\hline Well differentiated & $33(3.1)$ & $42(3.3)$ & & $26(3.4)$ & $27(3.5)$ & \\
\hline Moderately differentiated & $338(32.2)$ & $480(37.6)$ & & $263(34.1)$ & $269(34.8)$ & \\
\hline Poorly differentiated & $636(60.6)$ & $704(55.2)$ & & $452(58.5)$ & $443(57.4)$ & \\
\hline Anaplastic & $43(4.1)$ & $50(3.9)$ & & $31(4.0)$ & $33(4.3)$ & \\
\hline Tumor size, $\mathrm{mm} \pm \mathrm{SD}$ & $53.4 \pm 27.2$ & $49.9 \pm 25.8$ & 13.5 & $52.5 \pm 26.2$ & $52.3 \pm 28.2$ & 0.9 \\
\hline
\end{tabular}




\begin{tabular}{|c|c|c|c|c|c|c|}
\hline \multirow[b]{2}{*}{ Characteristic } & \multicolumn{3}{|c|}{ Unmatched cohort } & \multicolumn{3}{|c|}{ Propensity-matched cohort } \\
\hline & $\begin{array}{c}\text { Surgery }+ \text { AC } \\
(n=1050)\end{array}$ & $\begin{array}{c}\text { Surgery } \\
(\mathrm{n}=1276)\end{array}$ & $\begin{array}{c}\text { Standardized } \\
\text { difference }(\%)\end{array}$ & $\begin{array}{c}\text { Surgery }+\mathbf{A C} \\
(\mathrm{n}=772)\end{array}$ & $\begin{array}{c}\text { Surgery } \\
(\mathrm{n}=772)\end{array}$ & $\begin{array}{c}\text { Standardized } \\
\text { difference }(\%)\end{array}$ \\
\hline Surgical procedure, $\mathrm{n}(\%)$ & & & 12.8 & & & 4.2 \\
\hline Wedge resection & $77(7.3)$ & $128(10.0)$ & & $64(8.3)$ & $64(8.3)$ & \\
\hline Segmentectomy & $16(1.5)$ & $34(2.7)$ & & $16(2.1)$ & $12(1.6)$ & \\
\hline Lobectomy & $914(87.0)$ & $1066(83.5)$ & & $665(86.1)$ & $671(86.9)$ & \\
\hline Pneumonectomy & $43(4.1)$ & $48(3.8)$ & & $27(3.5)$ & $25(3.2)$ & \\
\hline Adjuvant radiation therapy, $\mathrm{n}(\%)$ & 387 (36.9) & $219(17.2)$ & 45.5 & $209(27.1)$ & $200(25.9)$ & 2.6 \\
\hline
\end{tabular}

Percentages are calculated after removing missing data from the specific variable in the table. $A C$, Adjuvant chemotherapy; $S D$, standard deviation.

more likely to have private insurance, were more likely to have a CDS of 0 , and had less differentiated and larger tumors. Patients who received AC were also more likely to be treated with lobectomy, were more likely to receive adjuvant radiation therapy, and were less likely to have had other cancers than lung cancer. There were no differences in the treating facility type (academic vs other) or the number of lymph nodes harvested (median of 8 in each group). Patients who did not receive $\mathrm{AC}$ were more likely to have Medicare and less likely to have adjuvant radiation therapy. Median survival for patients who received AC was 71 months (95\% confidence interval [CI], 59-81) compared with 39 months $(95 \% \mathrm{CI}, 36-44)$ in the resection-only group $(P<.001)$ (Figure 2$)$. Five-year survival was also significantly better in the AC group $(53 \%$ vs $38 \%$, $P<.001)$.

\section{Matched Comparisons}

We matched 772 patient pairs (1544 patients) from the 2326 eligible patients. The mean age was 65.3 years (56.4-74.2), the median tumor size was $52 \mathrm{~mm}$ (33-67), and 922 patients $(59.7 \%)$ were male. The 2 groups were well matched without differences in tumor size, treating facility type, race, primary payer, CDS, or receipt of adjuvant radiation therapy (Table 2). There was also no difference in the number of nodes examined between the 2 groups (both median of 8), but there was a small but statistically significant difference in 30-day readmissions, favoring the adjuvant therapy group $(4 \%$ vs $6.5 \%, P=.030)$. Patients receiving AC had significantly better overall survival (68 vs 39 months, $P<.001$ ) (Figure 3 ) and better 5 -year survival $(53 \%$ vs $38 \%, P<.001)$.

\section{DISCUSSION}

In the present study, using a large, retrospective, propensity-matched cohort from the NCDB, we show that AC improves overall survival in patients with T3N0 NSCLC that invades the chest wall. These findings corroborate current guidelines ${ }^{11}$ that recommend $\mathrm{AC}$ for patients with stage IIB tumors including patients with chest wall invasion without nodal metastases (N0) (Video 1).

There have been 7 relatively recent, large, randomized trials of patients with NSCLC that have compared surgery followed by AC with surgery alone..$^{6-8,12-14,19}$ Two of these studies have generated long-term survival data ( $>5$ years). ${ }^{5,15}$ Most of these trials offered platinum-based chemotherapy (except for Kato and colleagues ${ }^{19}$ ) and had a diverse patient population often including patients with stage I to IIIA NSCLC. Four of the trials showed an overall survival benefit. ${ }^{7,8,12,19}$ One did not, but showed survival benefits in subgroup analyses. ${ }^{6}$ Two studies did not show a survival benefit of AC administered to patients with resected lung cancer. ${ }^{14,17}$

Kato and colleagues ${ }^{19}$ randomized patients with resected stage I lung adenocarcinoma to chemotherapy (oral uraciltegafur) or observation. Most patients in the study had T1N0 disease and tumors larger than $2 \mathrm{~cm}$. Patients who received chemotherapy had better overall survival $(88 \%$

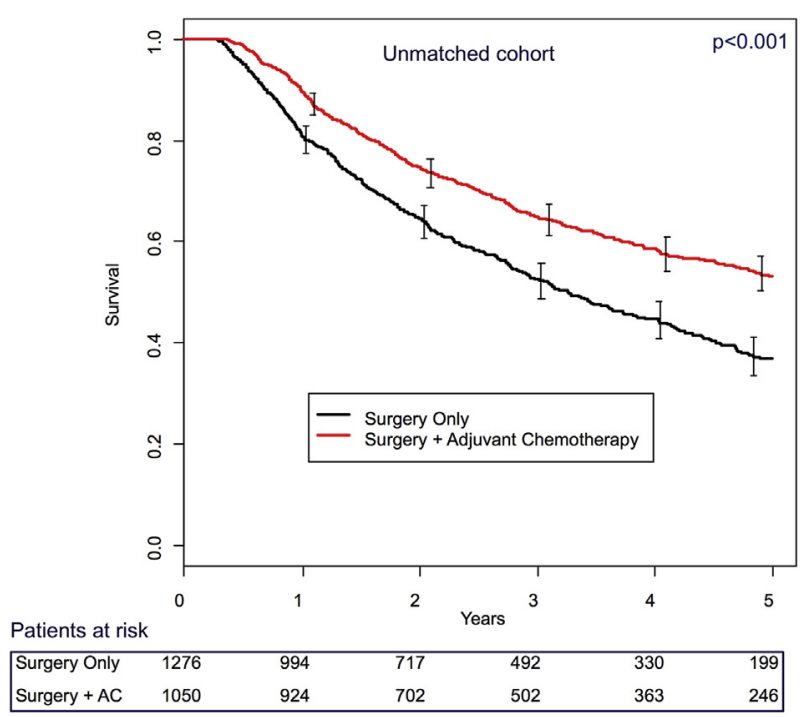

FIGURE 2. Overall survival in the unmatched cohort. $A C$, Adjuvant chemotherapy. 
TABLE 2. Matched cohort characteristics for patients with T3NO chest wall after complete resection

\begin{tabular}{|c|c|c|c|}
\hline Characteristic & Surgery + AC $(n=303)$ & Surgery $(n=303)$ & $P$ value \\
\hline Age at diagnosis, $\mathrm{y} \pm \mathrm{SD}$ & $65.4 \pm 8.9$ & $65.0 \pm 9.2$ & 5.2 \\
\hline Sex, n $(\%)$ & & & 1.3 \\
\hline Male & $172(56.8)$ & $174(57.4)$ & \\
\hline Female & $131(43.2)$ & $129(42.6)$ & \\
\hline Race, n (\%) & & & 8.2 \\
\hline White & $270(90.0)$ & $267(88.4)$ & \\
\hline Black & $26(8.7)$ & $26(8.6)$ & \\
\hline Other & $4(1.3)$ & $9(3.0)$ & \\
\hline Ethnicity, n (\%) & & & 1.2 \\
\hline Hispanic & $10(3.7)$ & $11(3.9)$ & \\
\hline Charleston Comorbidity Score, n (\%) & & & 8.9 \\
\hline Score 0 & $146(48.2)$ & $132(43.6)$ & \\
\hline Score 1 & $118(38.9)$ & $127(41.9)$ & \\
\hline Score $>1$ & $39(12.9)$ & $44(14.5)$ & \\
\hline Primary site, n (\%) & & & .9 \\
\hline Upper lobe & $248(81.8)$ & $249(82.2)$ & \\
\hline Middle lobe & $5(1.7)$ & $8(2.6)$ & \\
\hline Lower lobe & $50(16.5)$ & $46(15.2)$ & \\
\hline Laterality, n (\%) & & & 1.4 \\
\hline Right & $182(60.5)$ & $184(61.1)$ & \\
\hline Left & $119(39.5)$ & 117 (38.9) & \\
\hline Grade, n (\%) & & & 3.9 \\
\hline Well differentiated & $14(4.8)$ & $7(2.4)$ & \\
\hline Moderately differentiated & $108(37.4)$ & $119(40.9)$ & \\
\hline Poorly differentiated & $160(55.4)$ & $155(53.3)$ & \\
\hline Anaplastic & $7(2.4)$ & $10(3.4)$ & \\
\hline Tumor size, $\mathrm{mm} \pm \mathrm{SD}$ & $26.8 \pm 8.0$ & $27.0 \pm 7.5$ & 2.0 \\
\hline Institution, $\mathrm{n}(\%)$ & & & 7.5 \\
\hline Academic & $104(34.3)$ & $115(38.0)$ & \\
\hline Other & $199(65.7)$ & $188(62.0)$ & \\
\hline Surgical procedure, n (\%) & & & 4.2 \\
\hline Wedge resection & $42(13.9)$ & $54(17.8)$ & \\
\hline Segmentectomy & $7(2.3)$ & $8(2.6)$ & \\
\hline Lobectomy & $243(80.2)$ & $225(74.3)$ & \\
\hline Pneumonectomy & $5(1.7)$ & $7(2.3)$ & \\
\hline Adjuvant radiation therapy, $\mathrm{n}(\%)$ & $103(34.0)$ & $89(29.4)$ & 9.9 \\
\hline Primary payer, n (\%) & & & .5 \\
\hline Not insured & $4(1.3)$ & $12(4.0)$ & \\
\hline Private insurance & $110(36.3)$ & $94(31.0)$ & \\
\hline Medicaid & $21(6.9)$ & $20(6.6)$ & \\
\hline Medicare & $162(53.5)$ & $172(56.8)$ & \\
\hline Other/unknown & $6(2.0)$ & $5(1.7)$ & \\
\hline AJCC pathologic stage, $\mathrm{n}(\%)$ & & & 3.2 \\
\hline$<\mathrm{IIb}$ & $4(1.4)$ & $3(1.0)$ & \\
\hline $\mathrm{IIb}$ & $278(95.9)$ & $276(94.8)$ & \\
\hline$>\mathrm{IIb}$ & $8(2.8)$ & $12(4.1)$ & \\
\hline AJCC/TNM Edition, n (\%) & & & 4.7 \\
\hline 6th Edition & $174(57.4)$ & $167(55.1)$ & \\
\hline 7th Edition & $129(42.6)$ & $136(44.9)$ & \\
\hline
\end{tabular}

Percentages are calculated after removing missing data from the specific variable in the table. AC, Adjuvant chemotherapy; $S D$, standard deviation; $A J C C$, American Joint Committee on Cancer; $T N M$, tumor, node, metastases. 


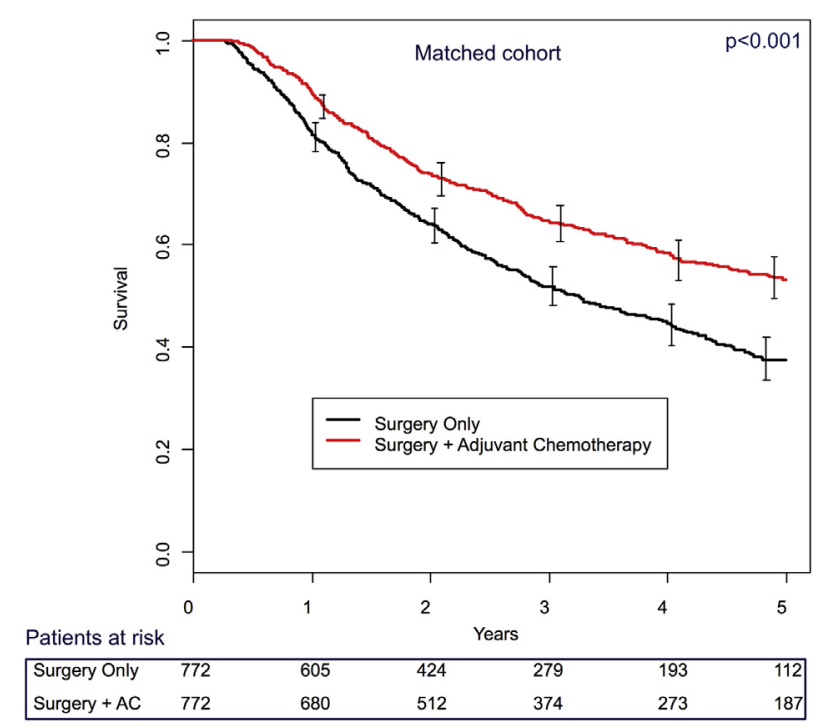

FIGURE 3. Overall survival in the matched cohort. $A C$, Adjuvant chemotherapy.

vs $85 \%$ 5-year survival) than those randomized to observation, but when the analysis was stratified by $\mathrm{T}$ stage, no difference in overall survival was seen for patients with $\mathrm{T} 1$ tumors and the advantage of $\mathrm{AC}$ was restricted to patients with T2N0 tumors.

The International Adjuvant Lung Cancer Trial randomized 1867 patients with stage I, II, or III NSCLC to surgery followed by chemotherapy (932 patients) or surgery followed by observation (935 patients). ${ }^{8}$ Approximately $25 \%$ of patients in the study had stage II NSCLC. Patients receiving chemotherapy had better overall survival and better 5-year survival $(44.5 \%$ vs $40.4 \%)$ than patients with surgery followed by observation. A follow-up to this study was published in 2010 and confirmed that survival at 5 years was improved by chemotherapy after surgery, but this effect decreased after 5 years, despite a continuing beneficial effect on lung cancer recurrence, suggesting the possibility of long-term toxicity of the chemotherapy. Patients aged more than 70 years and those with World Health Organization performance status of 2 benefited less from adjuvant therapy. ${ }^{19}$

The JBR 10 trial, a North American Intergroup phase III trial, ${ }^{16}$ included 482 patients with NSCLC: 240 in the surgery alone arm and 242 in the surgery and AC arm. The majority of patients had $\mathrm{T} 2$ tumors, and $55 \%$ had N1 disease. Adjuvant therapy significantly improved overall survival (69\% vs 54\% 5-year survival). A follow-up to the JBR 10 trial published 5 years after the original study showed that the benefit of chemotherapy was confined to patients with $\mathrm{N} 1$ disease and those with tumors larger than $4 \mathrm{~cm} .^{5}$

The Adjuvant Navelbine International Trialist Association $\operatorname{trial}^{7}$ randomized 840 patients with NSCLC (stages IIV) to surgery followed by chemotherapy (407 patients)

\section{Adjuvant Chemotherapy Improves Survival in Patients with Completely Resected, T3NO Non-Small Cell Lung Cancer Invading the Chest Wall}

\author{
Drake JA, Sullivan JL, Weksler B \\ Division of Thoracic Surgery \\ University of Tennessee Health Science Center/West Cancer Center \\ Memphis TN
}

\section{WEST}

VIDEO 1. Adjuvent chemotherapy for lung cancer. Video available at: http://www.jtcvsonline.org/article/S0022-5223(17)32857-X/fulltext.

or surgery alone (433 patients). There were slightly more patients with $\mathrm{N} 1$ or $\mathrm{N} 2$ disease compared with patients with N0 disease. Patients receiving chemotherapy had better overall survival, with the overall survival benefit of $8.4 \%$ at 7 years. Although the effect of chemotherapy was less noticeable in patients with stage IB NSCLC, the interaction between chemotherapy and tumor stage did not reach statistical significance.

The Cancer and Leukemia Group B 9633 trial $^{6}$ randomized 344 patients with $\mathrm{T} 2$ tumors to AC (173 patients) or observation (171 patients). Most patients (59\%) had tumors greater than $4 \mathrm{~cm}$. AC did not improve overall survival in this cohort, but subgroup analysis revealed that chemotherapy improved overall survival in patients with tumors larger than $4 \mathrm{~cm}$.

These trials demonstrated the important benefits of AC, but do not address specifically if patients with tumors that invade the chest wall benefit from adjuvant therapy. Several of the trials did not even study this tumor type, and those that did mixed patients with T3NO NSCLC and patients with N1 and N2 NSCLC for analysis. ${ }^{6,12,19}$ The overall effects in these trials are in the range of $3 \%$ to $15 \%$ improvement in 5-year survival, which is somewhat lower than the benefit of $15 \%$ seen in our study. In designing the present work, we did not think that there was a compelling evidence of benefits of adjuvant therapy in T3NO tumors with chest wall invasion. Rather, we thought that the evidence was inferential from the study of other similarly staged (N1 disease, large tumors) patients.

Ahmad and colleagues ${ }^{20}$ recently published a series of patients with T3N0 tumors using the NCDB. There were 569 patients who had surgery without adjuvant therapy and 255 patients who received AC. Five-year survival was $44 \%$ in patients receiving adjuvant therapy and $24 \%$ in patients not receiving $\mathrm{AC}$, and this effect is larger than in our study, likely because Ahmad and colleagues did not exclude patients who did not survive for 90 days. This was not a propensity score-matched study, and the 2 cohorts were 
different, with the surgery only being significantly older, suggesting uncontrolled selection bias. We attempted to control for selection bias by performing a careful propensity score matching.

\section{Study Limitations}

As with any large database study, there are inherent limitations in the data. The NCDB does not track disease-free survival and has limited information on comorbid conditions that could affect survival. Information on $\mathrm{AC}$ is limited, and we do not know which patients completed treatment. The NCDB also does not measure important variables that may influence survival, such as pulmonary function, functional status, and postoperative complications. Another important data point not provided by the NCDB is how many patients had only extrapleural dissection versus chest wall resection with or without reconstruction. As a retrospective large database, individual data points cannot be verified and errors may exist. Finally, there may be a subtle selection bias not detected in our analysis that made the practitioner decide on AC or not. This is suggested with the difference in 90-day mortality, significantly lower in the adjuvant therapy group, and possibly there were patients in the surgery only group who were just too sick postoperatively to tolerate adjuvant therapy. However, we do not believe these limitations compromise our major findings.

\section{CONCLUSIONS}

In a large database study, AC after complete (R0) resection was associated with significantly improved survival of patients with T3 NO NSCLC that invades the chest wall. Until the data from larger prospective randomized trials are available, AC should be considered for patients with T3N0 tumors that invade the chest wall.

\section{Webcast}

You can watch a Webcast of this AATS meeting presentation by going to: https://aats.blob.core.windows.net/media/ 17AM/2017-05-03/RM312/05-03-17_Room312_0838_ Drake.mp4.

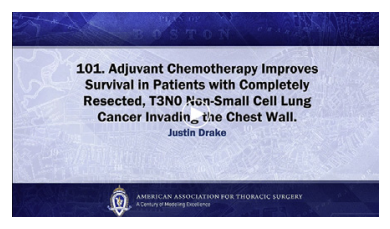

\section{Conflict of Interest Statement}

B.W. is a Proctor for Intuitive Surgery. The National Cancer Data Base is a joint project of the Commission on Cancer of the American College of Surgeons and the American Cancer Society. The Commission on Cancer's National Cancer Data Base and the hospitals participating in the Commission on Cancer's National Cancer Data Base are the source of the de-identified data used herein; they have not verified and are not responsible for the statistical validity of the data analysis or the conclusions derived by the authors. All other authors have nothing to disclose with regard to commercial support.

The authors thank Kevin Kennedy, MS, for expert biostatistical support, and Shannon Wyszomierski, $\mathrm{PhD}$, for expert scientific editorial review.

\section{References}

1. Ryerson AB, Eheman CR, Altekruse SF, Ward JW, Jemal A, Sherman RL, et al. Annual Report to the Nation on the Status of Cancer, 1975-2012, featuring the increasing incidence of liver cancer. Cancer. 2016;122:1312-37.

2. Riquet M, Arame A, Le Pimpec Barthes F. Non-small cell lung cancer invading the chest wall. Thorac Surg Clin. 2010;20:519-27.

3. Doddoli C, D'Journo B, Le Pimpec-Barthes F, Dujon A, Foucault C, Thomas P, et al. Lung cancer invading the chest wall: a plea for en-bloc resection but the need for new treatment strategies. Ann Thorac Surg. 2005;80:2032-40.

4. Lee CY, Byun CS, Lee JG, Kim DJ, Cho BC, Chung KY, et al. The prognostic factors of resected non-small cell lung cancer with chest wall invasion. World J Surg Oncol. 2012;10:9.

5. Butts CA, Ding K, Seymour L, Twumasi-Ankrah P, Graham B, Gandara D, et al. Randomized phase III trial of vinorelbine plus cisplatin compared with observation in completely resected stage IB and II non-small-cell lung cancer: updated survival analysis of JBR-10. J Clin Oncol. 2010;28:29-34.

6. Strauss GM, Herndon JE II, Maddaus MA, Johnstone DW, Johnson EA, Harpole DH, et al. Adjuvant paclitaxel plus carboplatin compared with observation in stage IB non-small-cell lung cancer: CALGB 9633 with the Cancer and Leukemia Group B, Radiation Therapy Oncology Group, and North Central Cancer Treatment Group Study Groups. J Clin Oncol. 2008;26: 5043-51.

7. Douillard JY, Rosell R, De Lena M, Carpagnano F, Ramlau R, GonzalesLarriba JL, et al. Adjuvant vinorelbine plus cisplatin versus observation in patients with completely resected stage IB-IIIA non-small-cell lung cancer (Adjuvant Navelbine International Trialist Association [ANITA]): a randomised controlled trial. Lancet Oncol. 2006;7:719-27.

8. Arriagada R, Bergman B, Dunant A, Le Chevalier T, Pignon JP, Vansteenkiste J, et al. Cisplatin-based adjuvant chemotherapy in patients with completely resected non-small-cell lung cancer. N Engl J Med. 2004;350:351-60.

9. Pignon JP, Tribodet H, Scagliotti GV, Douillard JY, Shepherd FA, Stephens RJ, et al. Lung adjuvant cisplatin evaluation: a pooled analysis by the LACE Collaborative Group. J Clin Oncol. 2008;26:3552-9.

10. NSCLC Meta-analyses Collaborative Group, Arriagada R, Auperin A, Burdett S, Higgins JP, Johnson DH, Le Chevalier T, et al. Adjuvant chemotherapy, with or without postoperative radiotherapy, in operable non-small-cell lung cancer: two meta-analyses of individual patient data. Lancet. 2010;375:1267-77.

11. Ettinger DS, Wood DE, Aisner DJ, Akerley W, Bauman J, Chirieac LR, et al. Non-small cell lung cancer, version 5.2017, NCCN clinical practice guidelines in oncology. J Natl Compr Canc Netw. 2017;15:504-35.

12. Winton T, Livingston R, Johnson D, Rigas J, Johnston M, Butts C, et al. Vinorelbine plus cisplatin vs. observation in resected non-small-cell lung cancer. $N$ Engl J Med. 2005;352:2589-97.

13. Scagliotti GV, Fossati R, Torri V, Crino L, Giaccone G, Silvano G, et al. Randomized study of adjuvant chemotherapy for completely resected stage I, II, or IIIA non-small-cell lung cancer. J Natl Cancer Inst. 2003;95:1453-61.

14. Waller D, Peake MD, Stephens RJ, Gower NH, Milroy R, Parmar MK, et al. Chemotherapy for patients with non-small cell lung cancer: the surgical setting of the Big Lung Trial. Eur J Cardiothorac Surg. 2004;26:173-82.

15. Arriagada R, Dunant A, Pignon JP, Bergman B, Chabowski M, Grunenwald D, et al. Long-term results of the international adjuvant lung cancer trial evaluating adjuvant Cisplatin-based chemotherapy in resected lung cancer. J Clin Oncol. 2010;28:35-42.

16. Bilimoria KY, Stewart AK, Winchester DP, Ko CY. The National Cancer Data Base: a powerful initiative to improve cancer care in the United States. Ann Surg Oncol. 2008;15:683-90.

17. Austin PC. Optimal caliper widths for propensity-score matching when estimating differences in means and differences in proportions in observational studies. Pharm Stat. 2011;10:150-61. 
18. Austin PC. Balance diagnostics for comparing the distribution of baseline covariates between treatment groups in propensity-score matched samples. Stat Med. 2009;28:3083-107.

19. Kato H, Ichinose Y, Ohta M, Hata E, Tsubota N, Tada H, et al. A randomized trial of adjuvant chemotherapy with uracil-tegafur for adenocarcinoma of the lung. $N$ Engl J Med. 2004;350:1713-21.

20. Ahmad U, Crabtree TD, Patel AP, Morgensztern D, Robinson CG, Krupnick AS, et al. Adjuvant chemotherapy is associated with improved survival in locally invasive node negative non-small cell lung cancer. Ann Thorac Surg. 2017; 104:303-7.

Key Words: lung cancer, surgery, adjuvant therapy

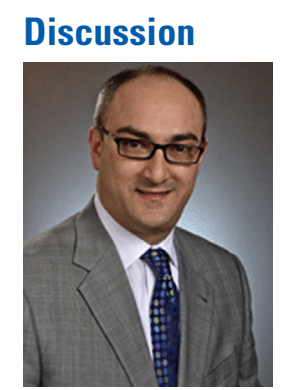

Dr M. Ebright (New York, NY). You and your colleagues attempt to traverse a murky area within our current staging system and treatment algorithms. As you state, the standard of care for these T3 N0 tumors according to National Comprehensive Cancer Network guidelines is resection followed by $\mathrm{AC}$, yet the actual treatment administered follows these guidelines at a surprisingly low rate. You illustrate how almost half of these patients do not receive any chemotherapy as part of their treatment algorithm in the NCDB, and according to our Society of Thoracic Surgeons database, patients receiving induction therapy for T3 N0 tumors far outnumber those who have superior sulcus tumors alone. This may be due in part to the disparate nature of T3 N0 disease, consisting of tumors invading the chest wall, diaphragm, mediastinum, and superior sulcus tumors and tumor metastasis within the same lobe, all with T3 N0. So this area is ripe for additional study. There is no clear standard of practice nationwide for these tumors.

I have 3 questions. The Charlson Comorbidity Index takes into account comorbid diseases but not true performance status. Is it possible that there was an inherent bias in the results where patients performing poorly after surgical resection were simply not fit for $\mathrm{AC}$ and therefore did not receive it?

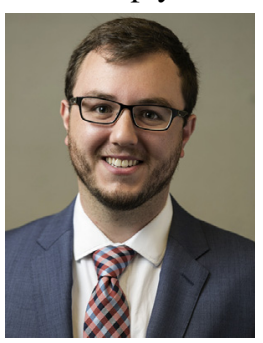

Dr J. Drake (Memphis, Tenn). The NCDB doesn't track any sort of performance status, it would be nice to have, but I think the Charlson Comorbidity Score is a nice surrogate for patients undergoing resection. People who tend to have a Charlson Comorbidity Score of 0 tend to do okay through the surgery. So it is a pretty good surrogate, I think.

Dr Ebright. What is the implication of the difference in care between those with Medicare and those with private insurance? Do you think this difference in care is simply a function of age and decreased performance status or something else?
Dr Drake. We didn't specifically look at which insurance got which therapies, but in our matched cohort we matched people with Medicare and people with private insurance pretty well, so I don't think that was a factor in our results at all.

Dr Ebright. The last question is more theoretical. Do you think there is something fundamentally different about the biology of these tumors which have the propensity to grow through the pleura and locally invade adjacent structures? For instance, do you believe that the pattern of recurrence is systemic rather than local for those who have an $\mathrm{R} 0$ resection?

Dr Drake. At this point, I think we could only speculate as to what the biology is. I think it would be something for a future study. Patterns of recurrence for these tumors are typically skipped into the mediastinum or distant metastases; that's what usually leads to mortality in lung cancer.

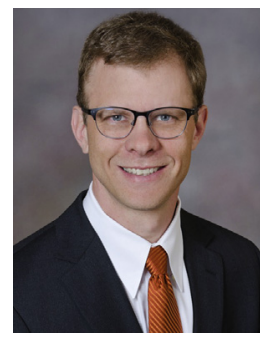

Dr P. Schipper (Portland, Ore). I want to push you just a little bit more on that first question, because I think the ability to receive $\mathrm{AC}$ is a marker for successful surgery, successful recovery. Is there anything in the NCDB that you could show us between these 2 groups that would describe how they recovered, complication rate, hospital length of stay, even the time period to when they started their chemotherapy?

Dr Drake. I would have to go back and look at the database, but I don't believe there is anything that looks at the patients directly postoperatively to see how they are doing, what their performance status is.

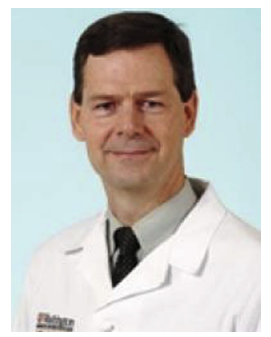

Dr B. Meyers (St Louis, Mo). I would counter your conclusions a bit. We looked at this phenomenon with esophageal cancer, and there are a lot of potential biases, but potentially they take you in different directions. For example, the younger, fitter patients who had no complications are more likely to be offered adjuvant therapy than the patients who really struggled. That would make adjuvant therapy look good. But then there are other things that might introduce bias. Patients who had a closer margin or a poorer prognosis, high-grade tumor, or lymphovascular invasion that was described, those might also be recommended to get chemotherapy. These biases make unrandomized assessment of AC look bad.

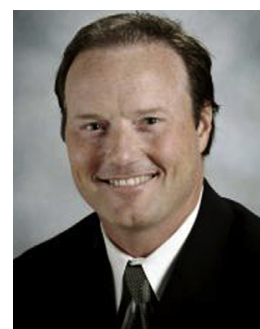

Dr W. Hofstetter (Houston, Tex). Benny, before you make a comment, I want to ask a question, which is, the overall benefit that you are showing is at $20 \%$ at 5 years, which is a huge benefit. Even the randomized trials for the smaller tumors without nodal disease, we're talking about a $4 \%$ overall benefit and with nodal disease maybe a $13 \%$ to $15 \%$ overall benefit. So what do you as a group attribute that large difference to? 


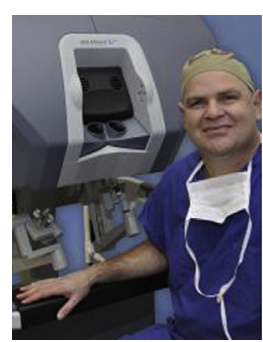

Dr B. Weksler (Memphis, Tenn). I think I will help Justin. Here is what I think about the NCDB. This is more of a signal-gathering database rather than a definitive database. So I think it shows that there is a potential benefit for chemotherapy in these patients, and I have no doubt that in randomized studies that a $20 \%$ difference is going to shrink toward the one that we know, of approximately $4 \%$ or $5 \%$ survival, and that's where the selection bias of the NCDB affects some of the data. In regard to early postoperative outcomes, I can tell you the NCDB tracks 30-day and 90-day mortality in R0 resection, and those were not different between those 2 groups. 